\title{
Power loss and right ventricular efficiency in patients after tetralogy of Fallot repair with pulmonary insufficiency: Clinical implications
}

\author{
Mark A. Fogel, MD, FACC, ${ }^{\text {a,b }}$ Kartik S. Sundareswaran, $\mathrm{PhD},{ }^{\mathrm{c}}$ Diane de Zelicourt, MS, ${ }^{\mathrm{c}}$ \\ Lakshmi P. Dasi, PhD ${ }^{\mathrm{c}}$ Tom Pawlowski, BS, ${ }^{\mathrm{a}}$ Jack Rome, MD, FACC, ${ }^{\mathrm{a}}$ and Ajit P. Yoganathan, $\mathrm{PhD}^{\mathrm{c}}$
}

Objectives: To quantify right ventricular output power and efficiency and correlate these to ventricular function in patients with repaired tetralogy of Fallot. This might aid in determining the optimal timing for pulmonary valve replacement.

Methods: We reviewed the cardiac catheterization and magnetic resonance imaging data of 13 patients with tetralogy of Fallot (age, $22 \pm 17$ years). Using pressure and flow measurements in the main pulmonary artery, cardiac output and regurgitation fraction, right ventricular (RV) power output, loss, and efficiency were calculated. The RV function was evaluated using cardiac magnetic resonance imaging.

Results: The RV systolic power was $1.08 \pm 0.62 \mathrm{~W}$, with $20.3 \% \pm 8.6 \%$ power loss owing to $41 \% \pm 14 \%$ pulmonary regurgitation (efficiency, $79.7 \% \pm 8.6 \% ; 0.84 \pm 0.73 \mathrm{~W}$ ), resulting in a net cardiac output of $4.24 \pm 1.82 \mathrm{~L} / \mathrm{min}$. Power loss correlated significantly with the indexed RV end-diastolic and end-systolic volume $(\mathrm{R}=0.78, P=.002$ and $\mathrm{R}=0.69, P=.009$, respectively). The normalized $\mathrm{RV}$ power output had a significant negative correlation with $\mathrm{RV}$ end-diastolic and end-systolic volumes (both $\mathrm{R}=-0.87, P=.002$ and $\mathrm{R}=-0.68, P=.023$, respectively). A rapid decrease occurred in the RV power capacity with an increasing $\mathrm{RV}$ volume, with the curve flattening out at an indexed RV end-diastolic and end-systolic volume threshold of $139 \mathrm{~mL} / \mathrm{m}^{2}$ and $75 \mathrm{~mL} / \mathrm{m}^{2}$, respectively.

Conclusions: Significant power loss is present in patients with repaired tetralogy of Fallot and pulmonary regurgitation. A rapid decrease in efficiency occurs with increasing RV volume, suggesting that pulmonary valve replacement should be done before the critical value of $139 \mathrm{~mL} / \mathrm{m}^{2}$ and $75 \mathrm{~mL} / \mathrm{m}^{2}$ for the RV end-diastolic and end-systolic volume, respectively, to preserve RV function. (J Thorac Cardiovasc Surg 2012;143:1279-85)

The repair of tetralogy of Fallot (TOF), ${ }^{1}$ which has pulmonary stenosis present, consists of placing a transannular patch across the right ventricular (RV) outflow tract to relieve the obstruction that results in pulmonary regurgitation (PR) and imposes a volume load on the RV. ${ }^{2,3}$ This RV volume load affects the RV function at rest as well as at exercise, and has been correlated with the degree of PR. ${ }^{4-6}$ Once the PR is abolished by placement of a competent pulmonary valve, exercise tolerance improves. ${ }^{7,8}$

We hypothesized that parameters such as RV volume, RV mass, and PR, which have been previously characterized in TOF, are surrogates to what is at the root of ventricular

\footnotetext{
From the Division of Cardiology, ${ }^{a}$ Department of Pediatrics, and Department of Radiology, ${ }^{b}$ Children's Hospital of Philadelphia, University of Pennsylvania School of Medicine, Philadelphia, Pa; and Wallace H. Coulter Department of Bioengineering, ${ }^{\text {c }}$ Georgia Institute of Technology, Atlanta, Ga.

Disclosures: Dr Fogel has a grant from the National Institutes of Health, Siemens Medical Solutions, and Edwards Life Sciences. Dr Yoganathan has a grant from the National Institutes of Health.

Received for publication Dec 7, 2010; revisions received May 31, 2011; accepted for publication Oct 24, 2011; available ahead of print Dec 12, 2011.

Address for reprints: Mark A. Fogel, MD, FACC, Division of Cardiology, The Children's Hospital of Philadelphia, 34th Street and Civic Center Boulevard, Philadelphia, PA 19104 (E-mail: fogel@email.chop.edu).

$0022-5223 / \$ 36.00$

Copyright (c) 2012 by The American Association for Thoracic Surgery doi:10.1016/j.jtcvs.2011.10.066
}

performance- $-\mathrm{RV}$ power output. Because the right ventricle must pump the regurgitant as well as the net stroke volume, we further hypothesized that this results in wasted power by the heart. The increased power needed might be a significant contributor to the etiology of ventricular dysfunction, ${ }^{5,6}$ exercise intolerance, ${ }^{4,5}$ and dysrhythmias that these patients experience. The quantification of this "wasted" power and its association with other parameters of ventricular performance might be the key toward understanding the limitations in patients with TOF and toward improving the medical, surgical, or catheter (eg, pulmonary valve replacement) management.

Cardiac magnetic resonance (CMR) cine imaging ${ }^{6}$ and phase contrast-CMR (PC-CMR) ${ }^{9}$ can accurately quantify the ventricular volume, cardiac index, and PR. Combined with measures of right-sided pressures by cardiac catheterization, power output, and power loss (PL) associated with $\mathrm{PR}$ and their association with standard measures of ventricular performance can be quantified. The hypothesis of the present study was twofold: significant PL is present in patients with TOF with PR; and that the PL has a significant effect on global ventricular function. We speculated that PL might be the global parameter that can explain decreasing RV function, could be the sentinel of deteriorating cardiorespiratory performance 


$\begin{array}{ll}\text { Abbreviations and } & \text { Acronyms } \\ \text { CMR } & =\text { cardiac magnetic resonance } \\ \text { TOF } & =\text { tetralogy of Fallot } \\ \text { PC-CMR } & =\text { phase contrast-CMR } \\ \text { PL } & \text { power loss } \\ \text { RV } & \text { right ventricular } \\ \text { RVEDVI } & \text { right ventricular end-diastolic } \\ & \text { volume indexed to standard } \\ & \text { clinical form } \\ \text { RVEDV }_{\text {Normalized }}= & \text { "normalized" right } \\ & \text { ventricular end-diastolic } \\ & \text { volume } \\ = & \text { right ventricular end-systolic } \\ & \text { volume indexed to standard } \\ \text { RVESVI } & \text { clinical form } \\ & =\text { "normalized" right } \\ \text { RVESV } & \text { ventricular end-systolic } \\ & \text { volume } \\ \text { RVOT } & =\text { right ventricular outflow tract } \\ \text { PR } & \text { pulmonary regurgitation }\end{array}$

and aid in determining the timing for pulmonary valve replacement.

\section{PATIENTS AND METHODS Patients}

Thirteen consecutive patients with repaired TOF and PR who underwent CMR and catheterization were enrolled in the present retrospective study, which was approved by the institutional review board. These patients underwent catheterization for possible interventional procedures (eg, stent placement, electrophysiologic testing). The patients with a peak velocity across the RV outflow tract (RVOT) of $>3 \mathrm{~m} / \mathrm{s}$ by echocardiography were excluded. The average interval between CMR and catheterization was $2 \pm 3$ months. All patients, except for 1 , underwent transannular patch repair of the RVOT; that patient underwent conduit placement. None underwent monocusp RVOT reconstruction or another valved type of intervention. Eight patients without right-sided lesions and normal right ventricles (5 with coarctation and 3 with aortic valve disease) were included as controls.

\section{CMR Imaging Protocol}

A standard electrocardiographic-gated CMR examination was performed on a 1.5-Tesla Siemens Avanto magnetic resonance system (Siemens Medical Solutions, Malvern, Pa). This consisted of static, steady-state, free precession for anatomy, cine CMR imaging for ventricular performance parameters (volumes), delayed enhancement to discern myocardial scarring, and PC-CMR for evaluation of the pulmonary flow. From PC-CMR imaging, the cardiac index was obtained. From cine CMR imaging, the ventricular function parameters such as RV enddiastolic volume, ejection fraction, and cardiac index were evaluated. Delayed enhancement imaging was used to determine myocardial scarring.

\section{Cardiac Catheterization}

Standard catheterization for TOF was performed. The oxygen saturation and pressure were obtained from both right- and left-sided structures according to the routine protocol. Catheterizations were performed for diagnostic reasons and intervention (stent placement) under sedation.

\section{Other Clinical Data}

Routine echocardiographic data were collected to determine the grade of tricuspid insufficiency and the assessment of the RVOT. Electrocardiograms were obtained to assess the QRS duration.

\section{Data Processing}

Ventricular function. The ARGUS software (ARUGUS Software, Houston, Tex), resident on Siemens workstations, was used to evaluate ventricular function. The endocardial borders were traced (semiautomatically) by an expert observer. The segmented CMR slices were integrated along the long axis using Simpson's rule to extract the total ventricular volumes.

Flow quantification. An in-house program using Matlab (MathWorks, Natick, Mass), described previously, ${ }^{10}$ was used to process the PC-CMR images. The regurgitant fraction is the reverse flow divided by the forward flow multiplied by 100 .

Evaluation of power output. Flow waveforms from PC-CMR and the systolic and diastolic pressures from catheterization were used to quantify the power output according to following equation:

$$
\text { Power }=\left(0.5 \cdot \rho \cdot v_{\text {mean }}^{2}+P_{\text {mean }}\right) \cdot Q_{\text {mean }} ;
$$

where $\rho$ is the blood density (a constant value of $1060 \mathrm{~kg} / \mathrm{m}^{3}$ ), $\mathrm{v}$ is the mean systolic velocity calculated in the systolic phase from PC-CMR $\left(\mathrm{Q}_{\text {mean }} /\right.$ Area $\left._{\text {mean }}\right), P_{\text {mean }}$ is the mean static systolic pressure measured in the main pulmonary artery during cardiac catheterization, and $\mathrm{Q}_{\text {mean }}$ is the mean flow rate in the systolic phase (forward flow, Figure 1) calculated from PC-CMR. The power output thus calculated is the mean power generated by the right ventricle in systole. This method has been used previously to evaluate the ventricular power output in single ventricle physiology. ${ }^{10}$

Evaluation of power loss. Similar to the power output, the PL due to PR was also evaluated using the previous equation. The mean diastolic pressure in the main pulmonary artery measured from catheterization was used as the $\mathrm{P}_{\text {mean }}$, the mean flow in the diastolic phase (backward flow, Figure 1) was used as the $\mathrm{Q}_{\text {mean }}$, and the mean backward velocity was used as the $\mathrm{v}_{\text {mean }}$, all derived from PC-CMR. The net efficiency was as follows:

$$
\text { Efficiency }(\%)=100 \cdot \frac{\text { Power }_{\text {Total }}-\text { Power }_{\text {Loss }}}{\text { Power }_{\text {Total }}}
$$

\section{Parameter Normalization}

Proper normalization of the parameters to account for patient-to-patient variability is necessary. The normalizing/indexing power using cardiac output or body surface area (BSA) assumes a linear relationship that might not be true because power is not linearly related to cardiac output or BSA. Dasi and colleagues ${ }^{11}$ have recently shown that $\rho \frac{Q^{3}}{B S A^{2}}$ (where $Q$ is the mean flow rate or cardiac output, and $\rho$ is the blood density) has the same dimension as power (Watts or $\mathrm{kg}-\mathrm{m}^{2} / \mathrm{s}^{3}$ ), and provides the appropriate normalizing parameter for power output, which transforms it to a dimensionless parameter (ie, dividing power by this parameter cancels out the dimensions, making the quotient dimensionless). Similarly, a dimensionless form of ventricular volumes was obtained by normalizing to $\mathrm{BSA}^{1.5}$, instead of the BSA alone. This is because the unit of measure for BSA ${ }^{1.5}$ is meters cubed, the same as for the ventricular volume. The dimensionless form of the ventricular volume is referred to as the "normalized" volume (RV end-diastolic volume $\left[\mathrm{RVEDV}_{\text {Normalized }}\right]$ and RV end-systolic volume). The present study also indexed the ventricular volumes to their standard 


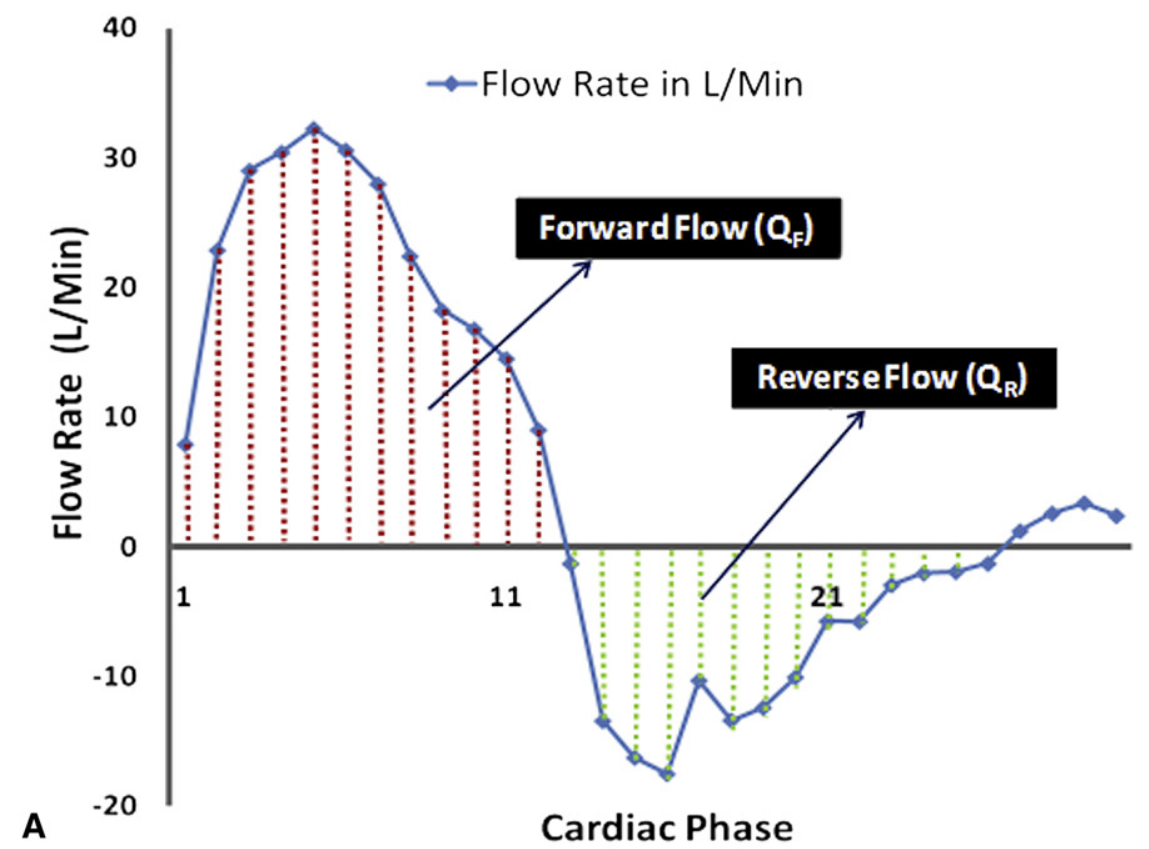

B

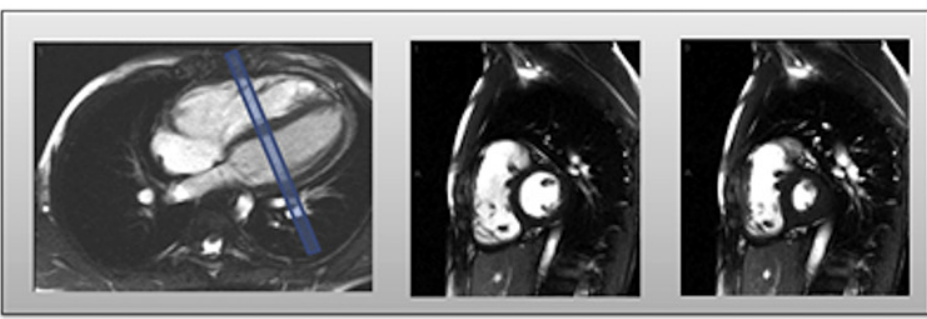

C

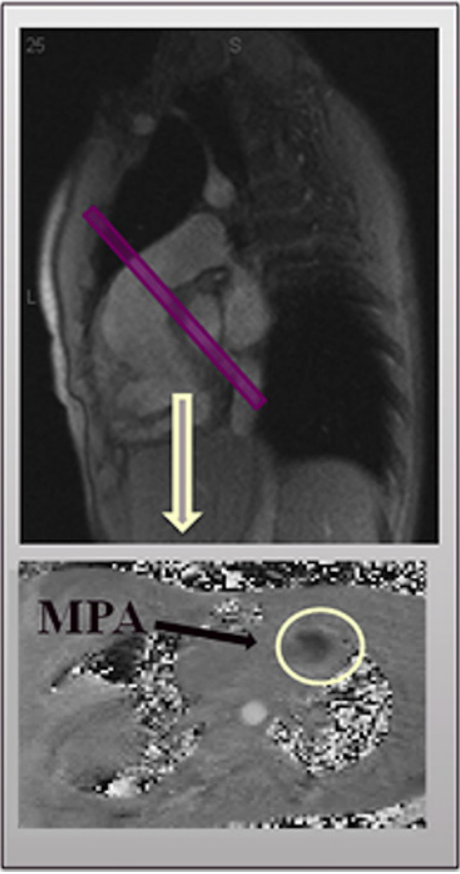

FIGURE 1. A, Typical main pulmonary artery (MPA) flow waveform in patients with tetralogy of Fallot (TOF) with pulmonary regurgitation $(P R)$ (top curve). The waveform is divided into forward and backward phases to evaluate the total right ventricular $(R V)$ power generated and power loss $(P L)$ due to pulmonary regurgitation $(P R)$. B, The images represent how the RV function and flow were obtained. Left, A 4-chamber view and short-axis views (rectangle on 4-chamber view) at end diastole and end systole (from left to right). C, Velocity map plane was obtained in the MPA (top) and an example of a velocity map (bottom). 
clinical forms using just the BSA $\left(\mathrm{mL} / \mathrm{m}^{2}\right)$, referred to as RVEDVI and RVESVI, respectively. The percentage of PL, percentage of ejection fraction, and percentage of power efficiency are dimensionless and do not require any additional normalization.

\section{Statistical Analysis}

All values are presented as the mean \pm standard deviation. Descriptive statistics were used for general characteristics of the population. The relationships between the power output and ventricular volumes were established using their normalized dimensionless forms. PL, hydraulic efficiency, PR, and QRS duration were correlated with the clinical indexes of RVEDVI and RVESVI, respectively. Statistical significance was set at $P<.05$. Correlations between different parameters were evaluated using Microsoft Excel (Microsoft, Redmond, Wash) and Systat (Cranes Software, Chicago, Ill). The Pearson coefficient of correlation was used to describe the nature of the parametric relationship.

\section{RESULTS \\ Baseline Characteristics and Standard Measures of Hemodynamics and Function}

The baseline characteristics and standard measures of hemodynamics and ventricular performance are listed in Table 1 . The right ventricle was dilated with a normal RV ejection fraction, and the LV size, ejection fraction, and cardiac output were normal. The QRS duration was prolonged $(137 \pm 33 \mathrm{~ms})$ and the mean PR was $41 \% \pm 14 \%$. The mean gradient across the RVOT was $12 \pm 21 \mathrm{~mm} \mathrm{Hg}$. Tricuspid insufficiency was trivial in 6 of 13 patients and mild in 6 patients. No significant aortic or mitral regurgitation was present. No myocardial scarring was noted in any of the patients; the RVOT patch demonstrated delayed enhancement in all patients. The control patient age was $12 \pm 6.7$ years, with a body surface area of $1.37 \pm$ $0.64 \mathrm{~m}^{2}$ and $0.21 \pm 0.26$ years from catheterization to CMR; none had PR.

\section{Power Evaluation}

The total RV power output was $1.08 \pm 0.62 \mathrm{~W}$. PR resulted in a PL of $0.24 \pm 0.18 \mathrm{~W}$, with a net RV power generation of $0.84 \pm 0.48 \mathrm{~W}$. This yielded an RV efficiency of $79.7 \% \pm 8.6 \%$. The total RV power output of the control patients was $0.8 \pm 0.6 \mathrm{~W}$, which appeared smaller than the total RV power output of the patients with TOF, although the difference was not statistically significant $(P=.32)$. It was similar to the net $\mathrm{RV}$ power generation of the patients with TOF $(P=.87)$. Figures 2 and 3 demonstrate the effect of PL on clinical indexes of RVEDVI and RVESVI, respectively. Significant positive correlations $(\mathrm{R}=0.78$ and $\mathrm{R}=0.69)$ were noted between PL and RVEDVI and RVESVI, respectively (Figure 2). The RV power efficiency, which takes into account the PL indexed to the total power output, was plotted against the RV volumes in Figure 3. A significant inverse relationship was noted between the efficiency and ventricular volumes $(\mathrm{R}=-0.78$ and $\mathrm{R}=-0.69$ for RVEDVI and RVESVI, respectively).
TABLE 1. Baseline characteristics

\begin{tabular}{|c|c|}
\hline Parameter & Value \\
\hline Age $(y)$ & $21.9 \pm 16.9$ \\
\hline Body surface area $\left(\mathrm{m}^{2}\right)$ & $1.34 \pm 0.6$ \\
\hline $\mathrm{RV}$ end-diastolic volume index $\left(\mathrm{mL} / \mathrm{m}^{2}\right)$ & $142 \pm 48$ \\
\hline $\mathrm{RV}$ end-systolic volume index $\left(\mathrm{mL} / \mathrm{m}^{2}\right)$ & $66 \pm 37$ \\
\hline RV ejection fraction $(\%)$ & $56 \pm 11$ \\
\hline $\mathrm{RF}(\%)$ & $40.5 \pm 13.8$ \\
\hline $\mathrm{LV}$ end-diastolic volume index $\left(\mathrm{mL} / \mathrm{m}^{2}\right)$ & $72 \pm 9$ \\
\hline LV end-systolic volume index $\left(\mathrm{mL} / \mathrm{m}^{2}\right)$ & $26 \pm 5$ \\
\hline LV ejection fraction $(\%)$ & $63 \pm 5$ \\
\hline $\begin{array}{c}\text { Systemic flow }\left(\mathrm{Q}_{\mathrm{s}}\right)(\mathrm{L} / \mathrm{min}) \\
(\mathrm{CMR} / \text { catheterization })\end{array}$ & $4.68 \pm 2.9 / 4.28 \pm 3.3$ \\
\hline $\mathrm{Q}_{\mathrm{p}}(\mathrm{L} / \mathrm{min})$ & $4.24 \pm 1.8$ \\
\hline Systemic vascular resistance (Wood units) & $26.2 \pm 9.7$ \\
\hline Pulmonary vascular resistance (Wood units) & $2.54 \pm 0.94$ \\
\hline RV end-diastolic pressure (mm Hg) & $4.3 \pm 3.6$ \\
\hline $\mathrm{RV}$ peak-systolic pressure (mm Hg) & $49.3 \pm 20.3$ \\
\hline $\mathrm{RV}$ mean systolic pressure $(\mathrm{mm} \mathrm{Hg})$ & $10.77 \pm 6.1$ \\
\hline LV end-diastolic pressure $(\mathrm{mm} \mathrm{Hg})$ & $6.7 \pm 4.8$ \\
\hline LV peak-systolic pressure $(\mathrm{mm} \mathrm{Hg})$ & $102.5 \pm 22.0$ \\
\hline LV mean systolic pressure $(\mathrm{mm} \mathrm{Hg})$ & $10.62 \pm 5.30$ \\
\hline Systolic pulmonary artery pressure $(\mathrm{mm} \mathrm{Hg})$ & $36.5 \pm 11.3$ \\
\hline Diastolic pulmonary artery pressure $(\mathrm{mm} \mathrm{Hg})$ & $9.4 \pm 4.5$ \\
\hline Systolic systemic blood pressure (mm Hg) & $102.6 \pm 18.4$ \\
\hline Diastolic systemic blood pressure $(\mathrm{mm} \mathrm{Hg})$ & $62.8 \pm 11.9$ \\
\hline QRS duration $(\mathrm{ms})$ & $137 \pm 33$ \\
\hline \multicolumn{2}{|l|}{ Tricuspid regurgitation } \\
\hline None & 1 \\
\hline Trivial & 6 \\
\hline Mild & 6 \\
\hline $\mathrm{RV}$ power output $(\mathrm{W})$ & $1.08 \pm 0.62$ \\
\hline Power loss (W) & $0.24 \pm 0.18$ \\
\hline Net efficiency $(\%)$ & $79.75 \pm 8.6$ \\
\hline
\end{tabular}

$R V$, Right ventricular; $R F$, regurgitant fraction; $L V$, left ventricular; $C M R$, cardiac magnetic resonance.

Figure 4 shows the relationship between the normalized $\mathrm{RV}$ total power output and the normalized RV volumes. A strong significant negative correlation was found between the normalized RV output power and $\mathrm{RVEDV}_{\text {Normalized. }}$ The RV power capacity decreased drastically as the RVEDV $_{\text {Normalized }}$ increased from 50 and 120 (120 is the inflection point at which the slope of the curve increases from $<-1$ to $>-1$ and at which the second derivative of this curve becomes 0 ). After 120, the curve flattens out, suggesting a possible critical state, after which the RV's ability to pump with adequate power diminishes. Because the mean BSA of the study population was $1.34 \pm 0.6 \mathrm{~m}^{2}$, the RVEDVI can be estimated to be $139 \mathrm{~mL} / \mathrm{m}^{2}(120 \mathrm{~mL} /$ $\left.\mathrm{m}^{3} \times 1.34^{0.5} \mathrm{~m}\right)$. Similarly, the RV power capacity decreased rapidly as the RVESVI increased, with an inflection point at a $R V E S V_{\text {Normalized }}$ of 65 (corresponding to a clinical RVESVI of $75 \mathrm{~mL} / \mathrm{m}^{2}$ ).

The mean LV power was $1.82 \pm 0.76 \mathrm{~W}$. Mitral and aortic valve regurgitation was absent or trivial in all patients; 

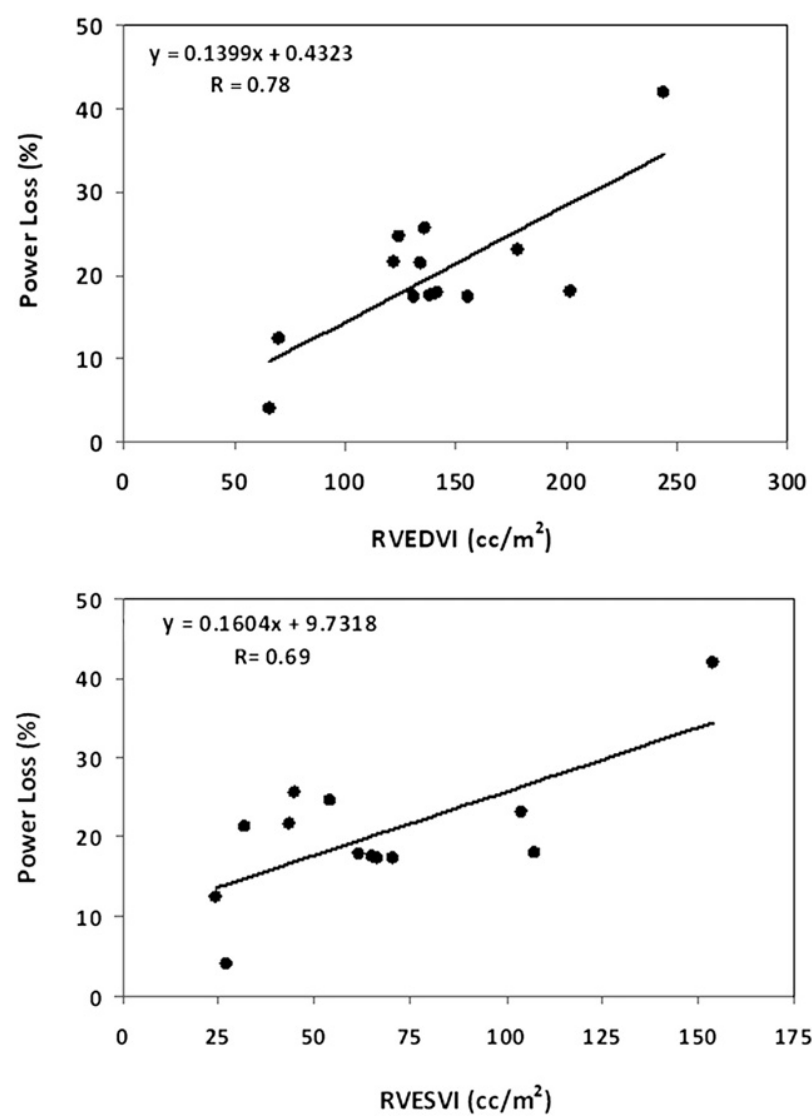

FIGURE 2. Relationship of right ventricular $(R V)$ power loss $(P L)$ with right ventricular end-diastolic volume index (RVEDVI) and right ventricular end-systolic volume index (RVESVI).

hence, all LV power was transferred to aortic flow (ie, PL on the left side was minimal).

\section{Correlations of RV Volumes and Power With Other Measures}

PR correlated well with both RVEDVI $(\mathrm{R}=0.79)$ and RVESVI $(\mathrm{R}=0.72)$. The $\mathrm{QRS}$ duration did not correlate with RVEDVI $(P=.806)$ or RVESVI $(P=.482)$. A relationship between the RVOT gradient and RV power output $(P=.35)$ and PL $(P=.24)$ was not present. Age also did not correlate with $\mathrm{RV}$ power output $(P=.27)$; however, it did correlate with PL $(\mathrm{R}=0.57, P=.04)$.

\section{DISCUSSION}

Power is simply energy per unit of time, and it would make sense that a heart that is required to pump a larger volume of blood must also expend more energy per unit of time to do so. The present study demonstrated that PL (average $\mathrm{PL}$ of $0.24 \mathrm{~W}$ in patients with TOF) can be assessed using a combination of CMR and catheterization. The mean value of the total RV power output of the patients with TOF was $1.08 \mathrm{~W}$ compared with $0.8 \mathrm{~W}$ in the control group. As expected, PL positively correlated with increasing RVEDVI,
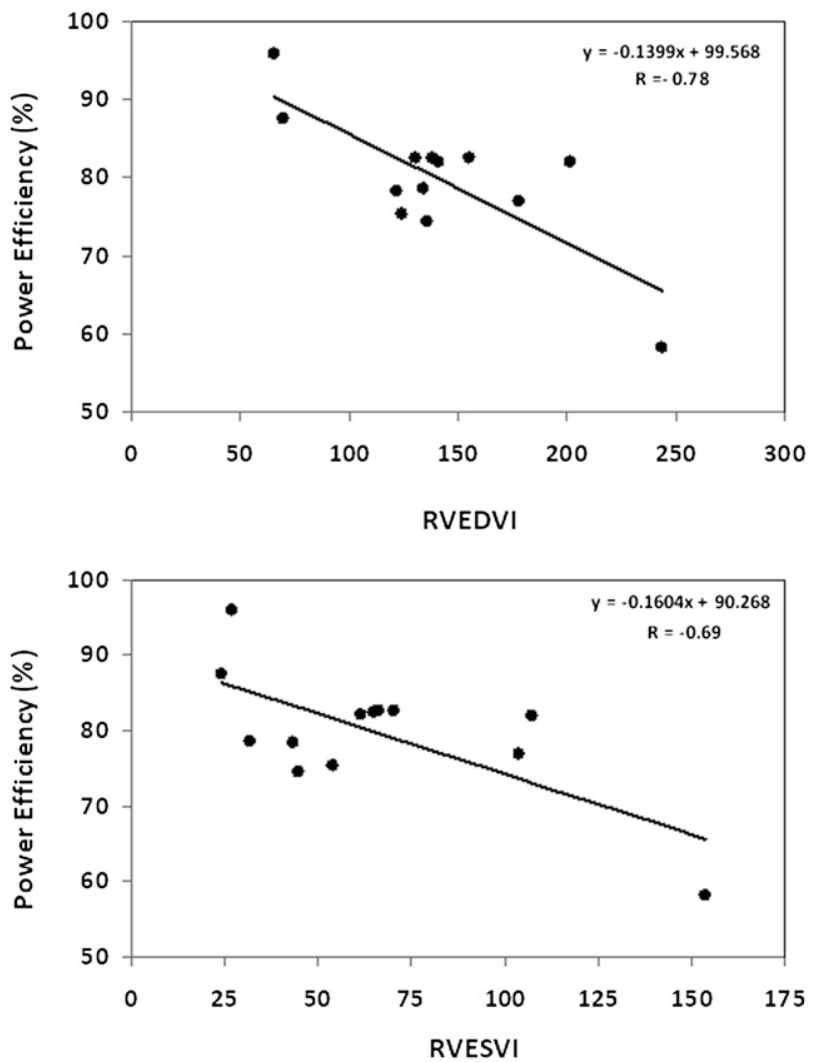

FIGURE 3. Relationship between total right ventricular $(R V)$ power efficiency and right ventricular end-diastolic and end-systolic volume indexes (RVEDVI and RVESVI, respectively).

RVESVI, and age. In addition, as the RVEDVI increased, a linear decrease occurred in RV efficiency, but a precipitous decrease occurred in the RV power output in an exponential fashion. The inflection point of the curve of RV power output versus RVEDV Normalized $_{\text {Was }} 120 \mathrm{~mL} / \mathrm{m}^{3}$, corresponding to an estimated RVEDVI of $139 \mathrm{~mL} / \mathrm{m}^{2}$.

Multiple studies have used routine parameters of ventricular function or flow to assess the postoperative TOF patient with PR. Nearly all have shown that depressed biventricular function is present at rest and during exercise using a number of different techniques such as CMR and radionuclide angiography. ${ }^{5,12}$ PR was correlated with a depressed LV ejection fraction $(r=-0.68)$ and exercise tolerance $(r=-0.50)$ by Niezen and colleagues. ${ }^{12}$ Wessel and $\mathrm{Paul}^{13}$ performed a review of 22 exercise studies from 1990 onward and found that 14 had found a significant relationship of the degree of PR with abnormal RV function and decreased exercise capacity.

There have also been attempts to correlate ventricular performance and clinical status. Knauth and colleagues, ${ }^{14}$ in a follow-up period of just longer than 4 years, found that a greater RVEDVI ( $>7$ standard deviations) and a lower $\mathrm{RV}$ ejection fraction $(<45 \%)$ correlated with an increasing 

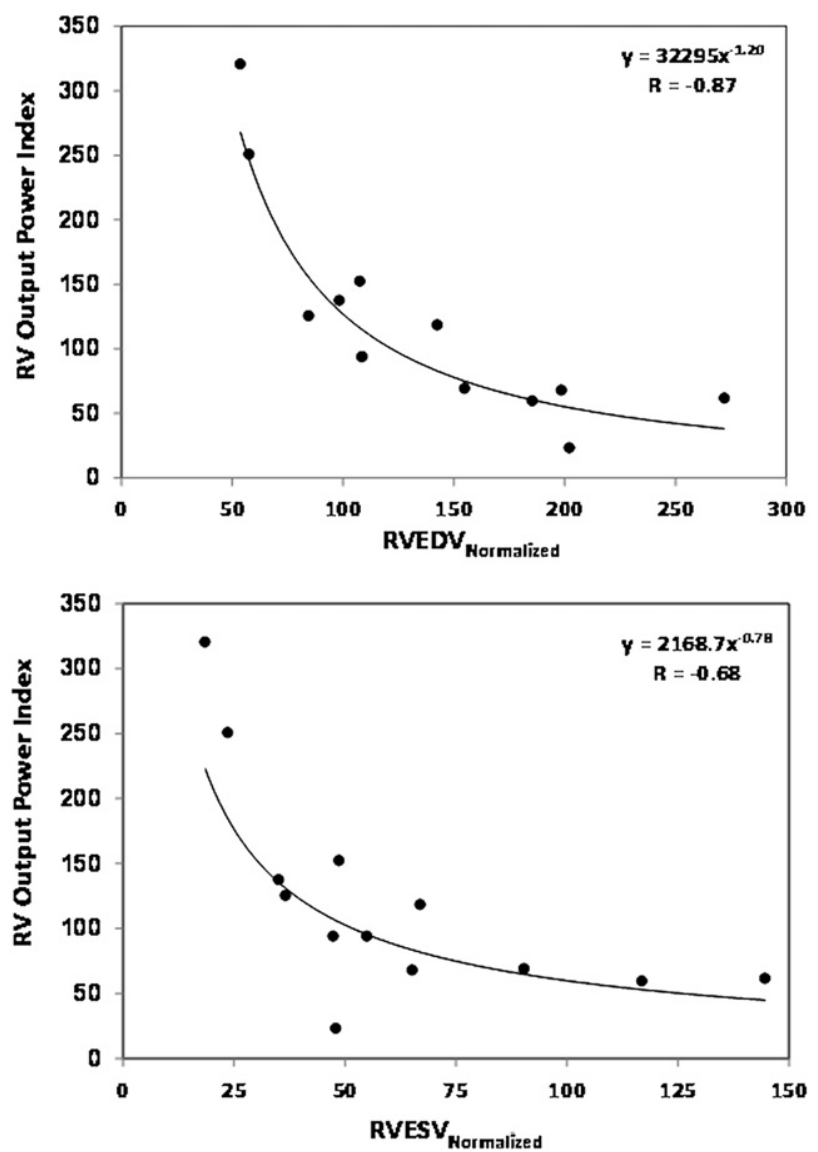

FIGURE 4. Relationship between normalized right ventricular $(R V)$ power output and normalized RV end-diastolic and end-systolic volume indexes ( $R V E D V_{\text {Normalized }}$ and $R V E S V_{\text {Normalized, }}$, respectively). Two sets of points (108.8 and 94.1 and 108.3 and 94.0) are right on top of each other and seem to appear as a single point.

probability of adverse events. An increasing New York Heart Association class has been found to be associated with lower LV ejection fraction (odds ratio, 3.88 for a $10 \%$ decrease; $P=.002$ ) and lower RV ejection fraction (odds ratio, 2.41 for a $10 \%$ decrease; $P=.01$ ). ${ }^{6}$ The regurgitant fraction, RVEDVI, and all the mentioned parameters result from the RV volume load due to the PR. These parameters are surrogates for the effect of the RV volume load on $\mathrm{RV}$ energetics, which is a more integrated assessment of function, drills down to ventricular performance on a more basic level and has been correlated with myocardial oxygen consumption. ${ }^{15}$ It could serve as a useful tool in predicting the clinical outcome and be a sentinel for deteriorating cardiorespiratory status.

Although this is the first study to demonstrate PLs in patients with TOF and its association with RV volumes, this is not the first study of power output or PL in congenital heart disease. Sundareswaran and collagues ${ }^{10}$ demonstrated that patients with hypoplastic left heart syndrome had a much lower power capacity than patients with other forms of single-ventricle morphology. In patients with Fontan circulation, Pekkan and colleagues ${ }^{16}$ demonstrated that a $7 \%$ decrease in energy losses corresponded with an $11 \%$ increase in cardiac output. Our laboratory has also shown a nonlinear, almost exponential increase in energy losses in the systemic venous pathway with increasing cardiac output. ${ }^{17}$

The findings of the present study, however, have implications beyond the realm of TOF and can be applied to other forms of heart disease. For example, repair of truncus arteriosus results in PR. Furthermore, the concept of PL in regurgitant lesions can be applied to adult valvular disease such as aortic or mitral insufficiency. PL could be a unifying concept and could possibly find utility as a predictor of outcomes; our findings might be the groundwork to investigate this concept in more detail.

PLs in the patient with TOF could have a clinical effect with regard to the timing of pulmonary valve replacement. $\mathrm{RV}$ volumes have been used as the key parameter in the past. Therrien and collagues ${ }^{18}$ studied 17 patients with TOF using CMR before and after pulmonary valve replacement and found that the RVEDVI and RVESVI decreased $34 \%$ and $37 \%$, respectively. Importantly, no patient achieved a normal RVEDVI and RVESVI after pulmonary valve competency if their RVEDVI before surgery was $>170 \mathrm{~mL} / \mathrm{m}^{2}$ and their RVESVI was $>85 \mathrm{~mL} / \mathrm{m}^{2}$. Valsangiacomo Buechel and colleagues ${ }^{19}$ performed a prospective study with CMR in patients with TOF of approximately 14 years with pulmonary valve replacement at an RVEDVI of greater than $150 \mathrm{~mL} / \mathrm{m}^{2}$. They found a significant decrease in the RV volumes and mass after valve replacement and significant remodeling 6 months after surgery, concluding that an RVEDVI of $150 \mathrm{~mL} / \mathrm{m}^{2}$ was a good clinical cutoff to undergo pulmonary valve repair. These studies corroborate our findings of using an RVEDVI of $139 \mathrm{~mL} / \mathrm{m}^{2}$ for pulmonary valve replacement, which is close to the cutoff from the study by Valsangiacomo Buechel and colleagues. ${ }^{19}$ After this point, a greater than 1 unit of volume change must occur in the reverse direction along the curve shown in Figure 4 to elicit a 1-unit change in power capacity. Hence, if valve replacement is performed before the cutoff, a greater improvement in ventricular power capacity can be achieved with ventricular remodeling. RV volumes greater than these values are operating on the flat part of the $\mathrm{RV}$ power output-RVEDVI curve, where the right ventricle has less power output and its energetics are least favorable. The importance of the timing of pulmonary valve replacement in patients with TOF should not be underestimated. Studies in the past decade have shown that once the right ventricle becomes too dilated, functional recovery is lacking. ${ }^{20,21}$

Our study is complementary to the recent report by Frigiola and colleagues, ${ }^{22}$ who had an aggressive pulmonary valve replacement strategy by operating on patients with an average RVEDVI of $142 \pm 43 \mathrm{~mL} / \mathrm{m}^{2}$, again very close 
to our value of $139 \mathrm{~mL} / \mathrm{m}^{2}$. They found that replacing the pulmonary valve early led to RVEDVI normalization, improvement in biventricular function, and much improved submaximal exercise capacity. It could be that because this group had a much lower RVEDVI threshold to operate, they were intervening at the steep part of the RV power output curve delineated in our study, preserving RV function and exercise capacity and facilitating improvement in RV power capacity.

\section{Study Limitations}

This was a retrospective study with all the inherent biases accompanying this type of investigation. We also studied a small group of patients. A prospective study is needed to determine whether an RVEDVI of $139 \mathrm{~mL} / \mathrm{m}^{2}$ and an RVESVI of $75 \mathrm{~mL} / \mathrm{m}^{2}$ should be used as the cutoff values to replace the pulmonary valve. CMR and cardiac catheterization occurred approximately 2 months apart and were not simultaneous with each other. No change in clinical status was noted between these 2 examinations, and it is unlikely that the interval in between these studies significantly affected our results. In addition, the light, conscious sedation used for catheterizations (ie, diazepam, meperidine, midazolam, and fentanyl in some combination) in the doses given generally have little effect on systemic and pulmonary vascular resistance. The catheterization team would not want to obtain data that were not reflective of the patient's true physiology. Therefore, we believe that this did also not significantly affect the results.

\section{CONCLUSIONS}

Patients with TOF after repair with PR experience PLs due to the regurgitant volume of just more than $20 \%$ on average, despite a regurgitant fraction of $41 \%$. The power output of the right ventricle decreases in an exponential fashion as the RV volume increases, with the curve flattening above an RVEDVI of $139 \mathrm{~mL} / \mathrm{m}^{2}$ and an RVESVI of $75 \mathrm{~mL} / \mathrm{m}^{2}$. The PL increases and RV power efficiency decreases with an increasing RV volume. This has implications for the timing of pulmonary valve replacement and could contribute to the decreased exercise performance in these patients. A prospective study is warranted.

We would like to thank Dr Alvin Chin for his assistance in data interpretation.

\section{References}

1. Campbell M. Incidence of cardiac malformations at birth and later, and neonatal mortality. Br Heart J. 1973;35:189-200.

2. Ruzyllo W, Nihill MR, Mullins CE, McNamara DG. Hemodynamic evaluation of 221 patients after intracardiac repair of tetralogy of Fallot. Am J Cardiol. 1974; $34: 565-76$
3. Poirier RA, McGoon DC, Danielson GK, Wallace RB, Ritter DG, Moodie DS, et al. Late results after repair of tetralogy of Fallot. J Thorac Cardiovasc Surg. 1977;75:900-8.

4. Sarubbi B, Pacileo G, Pisacane C, Ducceschi V, Iacono C, Russo MG, et al. Exercise capacity in young patients after total repair of tetralogy of Fallot. Pediatr Cardiol. 2000;21:211-5.

5. Kondo C, Nakazawa M, Kusakabe K, Momma K. Left ventricular dysfunction on exercise long term after total repair of tetralogy of Fallot. Circulation. 1995; 92(suppl II):II-250-5.

6. Geva T, Sandweiss BM, Gauvreau K, Lock JE, Powell AJ. Factors associated with impaired clinical status in long-term survivors of tetralogy of Fallot repair evaluated by magnetic resonance imaging. J Am Coll Cardiol. 2004;43: 1068-74.

7. Eyskens B, Reybrouck T, Bagaert J, Dymarkowsky S, Daenen W, Dumoulin M, et al. Homograft insertion for pulmonary regurgitation after repair of tetralogy of Fallot improves cardiorespiratory exercise performance. Am J Cardiol. 2000;85: 221-5.

8. Warner KG, Anderson JE, Fulton DR, Payne DD, Geggel RL, Marx GR. Restoration of the pulmonary valve reduces right ventricular volume overload after previous repair of tetralogy of Fallot. Circulation. 1993;88:II189-97.

9. Henk CB, Schlechta B, Grampp S, Gomischek G, Kelpetko W, Mostbeck GH Pulmonary and aortic blood flow measurements in normal subjects and patients after single lung transplantation at $0.5 \mathrm{~T}$ using velocity end coded cine MRI Chest. 1998;114:771-9.

10. Sundareswaran KS, Kanter KR, Kitajima HD, Krishnankutty R, Sabatier JF, Parks WJ, et al. Impaired power output and cardiac index with hypoplastic left heart syndrome: a magnetic resonance imaging study. Ann Thorac Surg. 2006; 82:1267-75

11. Dasi LP, Pekkan K, de Zelicourt D, Sundareswaran KS, Krishnankutty R, Delnido PJ, et al. Hemodynamic energy dissipation in the cardiovascular system: generalized theoretical analysis on disease states. Ann Biomed Eng. 2009;37: 661-73.

12. Niezen RA, Helgbing WA, van der Wall EE, van der Geest RJ, Rebergen SA, de Roos A. Biventricular systolic function and mass studied with MRI imaging in children with pulmonary regurgitation after repair for tetralogy of Fallot. Radiology. 1996;201:135-40.

13. Wessel HU, Paul MH. Exercise studies in tetralogy of Fallot: a review. Pediatr Cardiol. 1999;20:39-47.

14. Knauth AL, Gauvreau K, Powell AJ, Landzberg MJ, Walsh EP, Lock JE, et al Ventricular size and function assessed by cardiac MRI predict major adverse clinical outcomes late after tetralogy of Fallot repair. Heart. 2008;94:211-6.

15. Suga $H$. Total mechanical energy of a ventricle model and cardiac oxygen consumption. Am J Physiol Heart Circ Physiol. 1979;236:H498-505.

16. Pekkan K, de Zelicourt D, Ge L, Sotiropoulos F, Frakes D, Fogel MA, et al. Physics-driven CFD modeling of complex anatomical cardiovascular flows-a TCPC case study. Ann Biomed Eng. 2005;33:284-300.

17. Whitehead K, Pekkan K, Kitajima H, Paridon SM, Yoganathan AP, Fogel MA Non-linear power loss during exercise in single ventricle patients after the Fontan: insights from computational fluid dynamics. Circulation. 2007;116(suppl I): I165-71.

18. Therrien J, Provost Y, Merchant N, Williams W, Colman J, Webb G. Optimal timing for pulmonary valve replacement in adults after tetralogy of Fallot repair. $A m$ J Cardiol. 2005;95:779-82.

19. Valsangiacomo Buechel ER, Dave HH, Kellenberger CJ, Dodge-Khatami A, Petre R, Berger F, et al. Remodeling of the right ventricle after early pulmonary valve replacement in children with repaired tetralogy of Fallot: assessment by cardiovascular magnetic resonance. Eur Heart J. 2005;26:2721-7.

20. Warner KG, O’Brien PK, Rhodes J, Kaur A, Robinson DA, Payne DD. Expanding the indications for pulmonary valve replacement after repair of tetralogy of Fallot. Ann Thorac Surg. 2003;76:1066-72.

21. Geva T. Indications and timing of pulmonary valve replacement after tetralogy of Fallot repair. Semin Thorac Cardiovasc Surg Pediatr Card Surg Annu. 2006;11-22

22. Frigiola A, Tsang V, Bull C, Coats L, Khambadkone S, Derrick G, et al. Biventricular response after pulmonary valve replacement for right ventricular outflow tract dysfunction: is age a predictor of outcome? Circulation. 2008;118(suppl I): S182-90. 